\title{
Correction to: Teacher Feedback and Students' Self-regulated Learning in Mathematics: A Study of Chinese Secondary Students
}

\author{
Wenjuan Guo ${ }^{1} \cdot$ Jun Wei $^{2}$
}

Published online: 9 February 2019

(C) De La Salle University 2019

\section{Correction to: Asia-Pacific Edu Res}

https://doi.org/10.1007/s40299-019-00434-8

In the original publication of the article, the funding information was missed. It has been provided below.

Publisher's Note Springer Nature remains neutral with regard to jurisdictional claims in published maps and institutional affiliations.

Funding This research was sponsored by the Peak Discipline Construction Project of Education at East China Normal University.

The original article can be found online at https://doi.org/10.1007/s40299-019-00434-8.

Jun Wei

weijun@link.cuhk.edu.hk

Wenjuan Guo

juan.wenguo@163.com; minnieguo777@163.com

1 Faculty of Education, East China Normal University,

No. 3663, Zhongshan North Road, Putuo District, Shanghai,

China

2 Department of Educational Psychology, The Chinese University of Hong Kong, New Territories, Hong Kong, China 